\title{
O Cuidar na Concepção dos Cuidadores: um estudo com familiares de doentes crônicos em duas unidades de saúde da família de São Carlos-SP
}

\author{
The care in the design of caregivers: a study of patients with chronic family into two $u$ \\ nits of family health of São Carlos - SP \\ Cinira Conceição Longo Cardoso* \\ Maria Helena Pereira Rosalini** \\ Maria Tereza Mendes Laves Pereira***
}

\begin{abstract}
Resumo:
O presente estudo buscou analisar as alterações ocorridas na vida de pessoas que passaram a ser cuidadores, estando estes cadastrados nos territórios de duas Unidades de Saúde da Família de São Carlos-SP. Para isso, realizamos pesquisa de campo de abordagem qualitativa, sendo os dados coletados mediante a utilização de entrevista semiestruturada e analisados por meio da técnica de análise de conteúdo. A pesquisa demonstrou que todas as cuidadoras são do sexo feminino, ligadas ao dependente por vínculos de parentesco. As cuidadoras recebem pouco suporte econômico e psicossocial para desempenhar a função, representando uma sobrecarga e modificações em seus cotidianos. Também revelaram não ter obtido informações dos serviços de saúde quando iniciaram as práticas de cuidado, mas que com as atividades da Equipe de Saúde da Família sentem melhora no atendimento.
\end{abstract}

Palavras-chave: Cuidadores. Cuidar. Estratégia saúde da família.

\begin{abstract}
:
The present study looked for to analyze the alterations happened in the people's life that you started to be caretakers, being the same ones registered in the territories of two Units of Health of the Family of São Carlos-SP. For that, we accomplished research of field of qualitative approach, being the data collected by the use of interview itinerary semi-structured and analyzed through the technique
\end{abstract}

\footnotetext{
* Assistente social graduada pela Universidade Estadual de Londrina (UEL). Pós-graduada pelo curso de Residência Multiprofissional em Saúde Família e Comunidade da Universidade Federal de São Carlos (UFSCar). Terapeuta Comunitária pela Universidade Federal do Ceará. Assistente social da Defensoria Pública do Estado de São Paulo.

** Assistente social graduada pela Faculdade de Serviço Social de Piracicaba. Especialista em Saúde da Família pela Universidade Federal de São Carlos (UFSCar). Terapeuta Comunitária pela Universidade Estadual Paulista (UNESP). Em formação em Terapia Familiar pela Universidade Federal de São Paulo (UNIFESP). Chefe do Departamento de Serviço Social da UFSCar.

*** Assistente social graduada pela Universidade Estadual de Londrina (UEL). Mestre em Epidemiologia Clínica pela Universidade Federal de São Paulo (UNIFESP). Assistente social do Hospital Universitário de Londrina.
} 
of content analysis. The research demonstrated that all of the caretakers are female, linked to the dependent for blood ties. The caretakers receive little economical support and psychosocial to carry out the function, representing an overload and modifications in their daily ones. They also revealed not to have obtained information of the services of health when they began the care practices, but that feel improvement in the service with the activities of the Team of Health of the Family.

Keywords: Caretakers. To take care. Strategy health of the family.

\section{Introdução}

Atualmente podemos observar um número significativo de pessoas acometidas por doenças crônicas diversas, como os problemas cardíacos, a diabetes, a hipertensão, as doenças pulmonares, o câncer, os problemas de coluna, a aids, entre outras.

Para prestar atendimento a esses pacientes, existe uma rede de serviços nos sistemas público e privado de saúde. No público, essas pessoas podem receber atendimento no nível de atenção primário, ${ }^{1}$ secundário $^{2}$ e terciário. ${ }^{3}$

Na atenção primária ou básica está inserida a Estratégia Saúde da Família (ESF), que teve o início de sua implantação em 1994. Este Programa centra suas ações na realização de pré-natal, planejamento familiar, controle e prevenção da hipertensão, diabetes, doenças sexualmente transmissíveis, tuberculose, hanseníase, ou seja, muitas das patologias crônicas.

Os profissionais da ESF tratam essas doenças e seus agravantes e buscam um atendimento ampliado, conhecendo os fatores determinantes para a saúde e a doença, contribuindo, assim, para a melhoria da qualidade de vida das famílias atendidas. Além disso, as Unidades de Saúde da Família (USF) ficam mais próximas da população, permitindo a construção de vínculo entre usuários e profissionais, por meio dos atendimentos individuais, grupais e visitas domiciliares.

Esse trabalho é efetivado pela equipe de saúde da família composta por: médico da

\footnotetext{
${ }^{1}$ Conforme Elias (1998), neste nível está a Atenção Básica, visando a promoção da saúde e prestando atendimentos mais simplificados.

2 No nível secundário, concentram-se as especialidades ambulatoriais, incorporando tecnologia de equipamentos e profissionais mais especializados, visando o diagnóstico e tratamento periódico de doenças.

3 Já o nível terciário é representado pelos hospitais, incorpora modalidades de internação e intervenção cirúrgica, para diagnóstico e tratamento de doenças. Dispõe de equipe especializada com a finalidade de recuperação da saúde.
} 
família, enfermeiro, auxiliares de enfermagem, cirurgião dentista, auxiliares de consultório dentário e agentes comunitários de saúde.

A proposta de atendimento ampliado à população demandou a qualificação dos profissionais para trabalharem numa proposta de atendimento integral e humanizado a toda a família. Dessa forma, no município de São Carlos, no ano de 2007, por meio de uma parceria entre Universidade Federal de São Carlos (UFSCar) e Prefeitura Municipal, iniciou-se a Residência Multiprofissional em Saúde da Família e Comunidade (RMSFC). Esta é uma modalidade de especialização lato sensu, com o objetivo de formar e capacitar profissionais de saúde para atuarem no Sistema Único de Saúde (SUS).

Assim, ocorreu a inserção de diversos profissionais de saúde na rede, mais especificamente nas USF. A equipe de saúde da família passou a incluir os profissionais residentes: assistentes sociais, enfermeiros, educadores físicos, farmacêuticos, fisioterapeutas, fonoaudiólogos, nutricionistas, cirurgiões dentistas, psicólogos e terapeutas ocupacionais. Sendo que o trabalho dos residentes contribuiu para a ampliação e qualificação do acompanhamento às famílias, nos territórios de abrangência das USF.

Durante os atendimentos cotidianos nas USF, constatou-se diversos tipos de queixas e patologias, dentre essas um número significativo de doenças crônicas em fase de evolução, em que muitos dos pacientes passaram a precisar de ajuda para a realização de tarefas diárias, como tomar banho, cortar as unhas, escovar os dentes, alimentar-se, entre outros. Neste contexto, observou-se a figura do cuidador, pessoa que auxilia o paciente nas suas atividades cotidianas, sujeito de nossa pesquisa.

O cuidador passa a ser parte integrante da vida do paciente, deixando muitas vezes, em segundo plano, sua própria vida. Conforme Levorato (2006), o aumento das responsabilidades assumidas pelo cuidador interfere psicológica, física e socialmente na vida deste, pois suas ações diárias passam a se voltar exclusivamente para o familiar a ser cuidado.

Assim, há necessidade desses cuidadores terem visibilidade perante os serviços de saúde, que precisam estar atentos para que estes não adoeçam. Cabe aos profissionais das USF oferecer suporte aos cuidadores, conhecendo o contexto de vida e as dificuldades que enfrentam, a fim de desenvolverem ações que visem a melhoria da 
qualidade de vida do cuidador, tendo em vista a proposta de atendimento humanizado e integral.

Dessa forma, o estudo teve como objetivo geral analisar as modificações ocorridas na vida dos cuidadores-familiares, cadastrados nos territórios de duas Unidades de Saúde da Família do município de São Carlos e, como objetivos específicos, conhecer como se dá o processo de cuidar; verificar como ocorreu a designação do cuidador no contexto familiar; identificar os sentimentos vividos por eles; apontar se as USF contribuíram com o processo de cuidar vivenciado pelos cuidadores.

\section{Metodologia}

Trata-se de uma pesquisa de natureza qualitativa, aprovada pelo Comitê de Bioética da Universidade Federal de São Carlos. Para coleta de dados foi utilizada a técnica da entrevista semiestruturada e o uso do gravador. O roteiro de entrevista foi dividido em duas partes, a primeira para traçar o perfil dos cuidadores, e a segunda com questões que abordavam aspectos relacionados ao cuidador e o cuidar.

Os cuidadores participantes da pesquisa foram sete pessoas, cadastradas nos territórios de abrangência das USF. Todos assinaram um termo de consentimento livre esclarecido, conforme Resolução Federal no 196/96, do Conselho Nacional de Saúde, que dispõe sobre os aspectos ético-legais dos trabalhos de investigação científica. Aos participantes da pesquisa foi explicado o objetivo, finalidade do estudo, assegurando-lhes seu anonimato, uma vez que foram identificados neste estudo apenas a letra C (cuidador), respeitando a sequência das entrevistas C1, C2, C3, C4a e C4b (cuidadoras que exercem a atividade em conjunto), C5 e C6.

O estudo dos dados ocorreu por meio da análise de conteúdo, fundamentado em Minayo (1999, p. 74), “[...] através da análise de conteúdo, podemos encontrar respostas para questões formuladas e também confirmar ou não afirmações estabelecidas antes do trabalho de investigação [...]". Para examinar os resultados traçamos alguns eixos: identificação dos cuidadores; escolha do cuidador e suporte para desempenhar a atividade; o cuidar e suas implicações; o adoecer e os serviços de saúde. 


\section{Resultados e Discussão}

Identificação dos cuidadores

Ao entrarmos em contato com as pessoas que realizavam o cuidado dos pacientes, observamos somente cuidadores do sexo feminino, fato que confirma o que fala Floriani (2005) que, apesar do doente ficar aos cuidados da família, a tarefa é desempenhada, em sua maioria, por mulheres. Néri (apud KARSCH, 2003) complementa que isso é devido a causas culturais, sendo que o cuidar está relacionado à função da mulher na sociedade, muitas vezes com diversas atribuições, cuidado com os filhos, esposo, atividades domésticas e, em alguns casos, trabalho fora do lar.

Realmente todas as cuidadoras tinham responsabilidades familiares, além do cuidado que realizavam. Eram casadas, com exceção de uma que era divorciada, e todas possuíam vínculo de parentesco com o paciente cuidado, sendo: duas esposas, duas irmãs, duas noras e uma filha. A escolaridade variou desde não ter nenhuma formação escolar, possuir apenas ensino fundamental incompleto, até uma que possuía o Ensino Fundamental Completo. Suas fontes de subsistência variaram muito, sendo que uma era vendedora, trabalhando em sua própria casa; duas eram aposentadas; duas exerciam a função remunerada para cuidar, sendo que uma delas acumulava as funções de cuidado remunerado fora do lar e também cuidava do esposo; uma era cozinheira; uma não exercia atividade remunerada e não recebia benefício previdenciário, estava, portanto, em situação de vulnerabilidade, tendo em vista que contava com o auxílio de outros familiares para sua subsistência, de sua família e da pessoa que cuidava.

Pela característica dos territórios onde se inserem a USF, que têm famílias de baixa renda em situação de vulnerabilidade e famílias com vínculo empregatício na rede de indústrias e comercio da cidade, encontramos uma renda familiar das cuidadoras bastante diversa, variando de $R \$ 600,00$ a $R \$ 1650,00$, ou seja, de menos de um, até quase quatro salários mínimos. ${ }^{4}$ Considerando a existência de outras pessoas no domicílio, na maior parte dos casos a renda se torna, muitas vezes, insuficiente para a manutenção das despesas familiares, gerando nas cuidadoras um sentimento de fragilidade e impotência, pois a demanda de cuidados as impedem ou dificultam assumir trabalho fora do

\footnotetext{
${ }^{4}$ Durante a realização da pesquisa o valor do salário mínimo é de $\mathrm{R} \$$ 415,00.
} 
domicílio.

Com relação à idade das cuidadoras, a faixa etária variou de 29 a 77 anos, e da pessoa cuidada entre 59 e 88 anos. Já o tempo exercendo a função de cuidador foi de um (1) até vinte e quatro (24) anos. Notamos que algumas cuidadoras desempenham atividade por um longo período, o que pode agravar a saúde do cuidador.

Eu tinha seis anos quando comecei a cuidar dela [...]. Já tenho quase trinta anos como cuidadora [...] (C5).

Muitas das doenças físicas das cuidadoras estão relacionadas às atividades que exigem manuseio com o familiar dependente. Além disso, a maioria das cuidadoras estão na faixa etária de meia idade e três cuidadoras são idosas.

Muitos. Fibromialgia [...] dor de cabeça [...] problema na coluna, dor no ombro [...] eu tinha que colocar ela na patente e a pia é na frente da patente, ela grudava na pia, ai meu Deus do céu, eu acho que machucou esse ombro (C1).

Mendes (2005) em sua pesquisa constatou que há uma faixa etária idosa cuidando dos também idosos dependentes. Sendo que esses cuidadores têm um risco maior de apresentar doenças crônicos-degenerativas, como dores lombares, depressão, pressão alta, artrite, reumatismo, problemas cardíacos e diabetes. Fatores esses que podem dificultar o exercício da função de cuidador.

As atividades de cuidar estão relacionadas ao auxílio nos hábitos de vida diária, no uso da medicação, na higiene pessoal, passeio, entre outros (INOCENTI; RODRIGUES; MIASSO, 2009). Dessa forma, há dedicação integral à pessoa cuidada, que somada ao grande período na atividade justifica o desgaste físico e emocional do cuidador, demandando uma necessidade de cuidado próprio, para suportar sem adoecer.

Em relação aos cuidados próprios, três das cuidadoras relataram não realizar nenhum tipo de tratamento, devido à falta de tempo. As outras relatam fazer uso de medicação ou práticas alternativas.

[...] Simpatia para ver se melhora. Eu evito tomar muito esses remédios. Eu acho assim, melhora de um lado, mas piora de outro [...] (C1). 
Assim como apontou Caldas (apud SANTOS, 2003), percebemos que há uma preocupação dos cuidadores por não estarem se cuidando, contudo relatam ter dificuldades em conciliar suas atividades de cuidar e o autocuidado.

Esse é um dado que requer um olhar atencioso da equipe de saúde, pois além do risco de não poder mais cuidar do paciente sob seus cuidados, pode ser mais uma pessoa a desenvolver doenças, que poderiam ser cuidadas preventivamente.

Se o cuidador é uma pessoa que cuida de um paciente crônico, por que não considerá-lo um paciente que precisa de cuidado no domicílio, dada a sua vulnerabilidade e sua impossibilidade de distanciar-se do paciente sob sua responsabilidade?

\section{Escolha do Cuidador e Suporte para Desempenhar a Atividade}

Conforme Wanderley (1998) e Mendes (2005) existem diversas classificações de cuidadores. O cuidador principal é o que tem maior ou total responsabilidade nos cuidados ao dependente, como é o caso dos sujeitos da pesquisa. Já os secundários são os familiares, voluntários e profissionais que prestam algumas atividades complementares.

Em nossa pesquisa, a escolha do cuidador principal esteve relacionada a fatores como vínculo de parentesco, valores morais, matrimoniais e necessidade de substituição de cuidador devido ao seu adoecimento.

Ela morava em São Paulo [...] e sempre que eu ia passear lá eu convidava ela para morar comigo [...] e ela topou. Quando fazia um ano e cinco meses que ela tava morando comigo deu o derrame cerebral nela. Acabou ficando aqui nessas condições (C2).

De acordo com Mendes (2005), são quatro fatores principais para a designação do cuidador: parentesco (cônjuges, filhos); gênero (na maioria mulheres); proximidade física (quem vive com a pessoa); proximidade afetiva (com destaque para a relação entre cônjuges e entre pais e filhos).

Quanto à experiência anterior de cuidar, apenas duas haviam vivenciado. Uma das cuidadoras cuidou da mãe e uma praticava atividade formal como cuidadora. As 
experiências anteriores de cuidar são importantes, pois o cuidador teve oportunidade de aprender práticas de manejo com o doente. Porém, experiências anteriores podem também representar uma sobrecarga.

Em relação ao suporte que as cuidadoras recebem de seus familiares observamos que apenas uma pessoa recebia ajuda financeira. Já o apoio psicossocial para os cuidados com os doentes vinha em momentos em que o cuidador principal não tinha como estar presente, por necessidade de trabalhar ou problemas pessoais. Também pudemos constatar nas falas a presença de cuidadores remunerados, que estabeleciam vínculos profissionais para exercer a atividade de cuidar.

Não, de ninguém, nem ajuda para cuidar e nem dinheiro, nada, nada [...]. Eles não me ajudam, nem perguntam do que eu preciso. [...] Agora eu to pagando uma mulher, pago $R \$ 150,00$ por mês. Ela vem cedo pra dar banho, meio dia ela olha, se mijou troca, se não mijou não troca e a tarde, umas 6 horas. Se precisar mais eu ligo e ela vem (C3).

As cuidadoras não recebem muito apoio de seus familiares, o que prejudica a renda familiar e ocasiona diminuição da vida social e relações familiares, devido a impossibilidade de sair de casa e falta de substituto na função.

Sobre o apoio de outros familiares, Silveira e Caldas (2006) relatam que tendem a ocorrer mudanças no âmbito familiar como o afastamento dos parentes, sendo que não oferecem apoio emocional e financeiro.

Segundo Karsch (apud CATTANI; GIRARDON-PERLINI, 2004, p. 261),

[...] assumir o fato de ser responsável pelo cuidado não é uma opção, porque, em geral, o cuidador não toma a decisão de cuidar, mas esta se define na indisponibilidade de outros possíveis cuidadores para cuidar e, quanto mais o cuidador se envolve, mais os não-cuidadores se desvencilham do cuidado. Assim, percebemos que, uma vez assumido, o cuidado dificilmente é transferível.

\section{O Cuidar e suas Implicações}

Sobre o relacionamento com a pessoa cuidada as cuidadoras afirmaram:

Eu também. Ele não era muito calmo, tem um gênio difícil, mas é uma ótima pessoa [...]. É difícil, não sei se na cabeça dele, ele fala e acha que 
tá saindo. Não sei se tem noção de que a gente não tá entendendo. Então é difícil para ele. Fala uma coisa, não é isso, fala outra, não é isso. Por fim a pessoa vai ficando nervosa, porque tá falando e você não tá entendendo (C4b).

Uma cuidadora afirmou que quase não tinha contato com o irmão devido as suas idas frequentes ao bar, e que hoje prefere não estabelecer muito diálogo com este. Notamos que dificuldades de relacionamento no passado podem interferir negativamente no cuidado. As demais cuidadoras afirmaram bom relacionamento com os familiares antes e depois do adoecimento.

Porém, podemos notar que existem muitas dificuldades relacionadas à comunicação, fazendo com que apareçam sentimentos de nervosismo e impotência por não compreender o doente.

Mendes (2005) relata sobre a diversidade de sentimentos que afloram o cuidador: amor, impotência, pena, alívio, culpa, vergonha e, muitas vezes, revolta pela dependência de si e do outro.

Sobre a comunicação, Santos (2003, p. 81) afirma que os cuidadores sentem dificuldades em aceitar a condição de dependentes de seus familiares: "[...] Isso talvez aconteça porque culturalmente nos habituamos a comunicar e a interagir através do nosso corpo, pois é ele que nos dá visibilidade no processo de interação social".

Constatamos também que o cuidar é uma tarefa absorvente e que ocasiona modificações na vida dos cuidadores. Todas as entrevistadas referem modificações em suas vidas após assumirem os cuidados, estando estas relacionadas à falta de tempo para o exercício de atividades sociais, mudanças econômicas devido ao aumento de gastos e dificuldades para trabalhar.

Conforme Seltzer e Li (apud ALTAFIM, 2007) e também Brito (2009), os pesquisadores têm proposto dividir o conceito de impacto em dois componentes: subjetivo e objetivo. O objetivo empregado aos problemas práticos da vida diária (relações familiares, alterações no emprego e na renda, estado de saúde, redução das atividades sociais), já o subjetivo refere-se à reação emocional do cuidador.

Quanto às atividades sociais, as cuidadoras referem não ter tempo para realizá-las, como frequentar a Igreja, local considerado por algumas delas importante como suporte. 
Ai minha filha é a mesma coisa de uma noite escura e um dia claro. Porque antes dela vir morar comigo, ou quando ela tava boa, ela falava para mim, você quer sair pode sair, quer ir na Igreja pode ir, eu fico bem, sou acostumada a ficar sozinha. Então eu saia, ia fazer o meu trabalho de pregação [...]. Nosso Pai do Céu dá muita força, dá muita força pra gente $[\ldots](C 2)$.

Santos (2003) afirma em sua pesquisa que as práticas religiosas foram percebidas pelos cuidadores como estratégias muito eficazes de enfrentamento da sobrecarga, da angústia, do estresse e da depressão decorrentes do processo de cuidar.

Quanto às modificações econômicas apenas uma cuidadora relatou não tê-las sentido significativamente. As demais cuidadoras citaram aumento nas contas de água, energia elétrica, alimentação, despesas com as modificações na residência e aquisição de equipamentos.

\begin{abstract}
Aumentou gastos principalmente na água, energia. A alimentação é por sonda, minha filha pega às vezes no Postão, mas quando tem que comprar é $R \$ 46,50$ e uma lata dura três dias. Teve que fazer mudança na casa. A cama dela foi meu filho que fez. A gente tinha alugado uma cama de hospital para ela, [...] aluguel da cama você já pensou? [...] Meu filho veio passear aqui olhou a cama e disse, isso eu faço [...] Ela ergue até a metade e é melhor porque ela tem rodinhas (C2).
\end{abstract}

Quanto aos equipamentos, como cama hospitalar, cadeira de rodas, cadeira de banho, não foram obtidos pelo poder público, mas sim com a ajuda de outros cuidadores que tiveram seus familiares falecidos ou por meio de aluguel. Uma cuidadora também contou com a criatividade de outro familiar para fazer uma cama de hospital, diminuindo, assim, despesas com aluguel.

Conforme Santos (2003), as dificuldades financeiras interferem negativamente no processo de cuidar, pois impedem ou dificultam a compra de alimentos, medicamentos e equipamentos. No caso de nossas entrevistadas, superaram tais dificuldades com auxílio e formas criativas.

Apenas uma cuidadora não realizou modificações na residência. As demais relataram ter realizado ampliação na casa, mudanças de quarto, da disposição de objetos (tapetes, sofá como apoio).

Felgar (2004) constatou em sua pesquisa que houve reformas nos domicílios dos 
cuidadores entrevistados. Sendo que espaços foram subdivididos ou criados anexos para aumentar o número de cômodos.

Quanto às atividades laborativas, duas cuidadoras deixaram de trabalhar para assumir os cuidados do familiar. Porém, mediante a falta de recursos financeiros, voltaram a exercer atividades laborativas em horários que pudessem contar com o auxílio de outros familiares.

Mudou muito. De marido passa a ser praticamente filho. A gente passa a ser uma pessoa que cuida da saúde, troca, como se fosse uma criança. Deixei de trabalhar porque teve uma época que ele tava ruim, muito depressivo [...]. A gente paga aluguel, fica difícil. O dinheiro que meu filho recebe é pra aluguel, água e luz, o que eu recebo é pra comprar comida, remédio que não tem aqui. Então, eu não posso parar de trabalhar (C6).

Segundo Fonseca, Penna e Soares (2008), embora ocorram alterações financeiras, devido ao aumento das despesas com os cuidados do familiar dependente, há dificuldades em conciliar o cuidado do familiar e o trabalho fora de casa, fazendo com que os cuidadores tenham que deixar o trabalho.

Karsch (1999) discorre sobre a falta de amparo das autoridades sobre os cuidadores, sendo que estes não têm suporte de serviços externos, políticas e programas.

[...] o resgate e a valorização do papel da família, da comunidade e do esforço voluntário não deve significar a desresponsabilização do papel do Estado nos seus diversos níveis de governo (federal, estadual e municipal), mas o caminho para a articulação de esforços do setor público, do setor privado e da sociedade civil na busca de saídas que se pautem pela efetiva solução dos problemas (WANDERLEY et al., 1998, p. 12).

Já expostos o cotidiano e as dificuldades dos cuidadores, discorremos a seguir sobre o significado do cuidar que assume diferentes conotações pelas cuidadoras entrevistadas.

Cuidar é um zelar do outro [...]. Deixar comida, dar banho, cuidar direitinho, tratar bem. Não maltratar, não magoar com palavras, porque isso dói muito. [...] Zelo, brinco com ele, faço graça com ele, procuro fazer o melhor (C6). 
Notamos que uma cuidadora vincula o cuidado a um valor moral. Duas cuidadoras relacionam o cuidar às atividades práticas, como higiene, alimentação e tomada de medicação. Três cuidadoras citam valores afetivos e uma vincula sentimentos de afeto e práticos.

Conforme Conceição (2010, p. 84),

O preparo de cuidadores exige a definição de uma base conceitual norteadora dos valores e princípios filosóficos, que podem ser reconhecidos pelos seguintes pressupostos: 1 . o cuidador humano no ou o "autocuidado" representa a essência da condição humana. O "cuidar do outro", sempre representa condição temporária e circunstancial, à medida que o "outro" está impossibilitado de se cuidar; 2. o "cuidador" é uma pessoa envolvida no processo de "cuidar do outro" [...].

Segundo Mendes (2004), o cuidar é um conjunto de ações que envolvem administração de medicação, dieta alimentar, higiene pessoal, realizar exercícios entre outras.

Já Boff (1999) refere que o ato de cuidar representa uma atitude de responsabilização, preocupação e envolvimento afetivo. Dessa forma, cuidar é mais do que um ato é uma atitude. O cuidado existe quando se dedica ao outro, participando de suas buscas, sucessos, sofrimentos, enfim de sua vida. O cuidador sai de si e centra-se no outro.

O grande desafio para o ser humano é combinar trabalho com cuidado. Eles não se opõem, mas se compõem. Limitam-se mutuamente e ao mesmo tempo se complementam. Juntos constituem a integralidade da experiência humana, por um lado, ligada à materialidade e, por outro, à espiritualidade (BOFF, 1999, p. 99).

Após a apresentação das cuidadoras sobre o cotidiano de cuidados com o familiar, dificuldades e concepções sobre o cuidar, apresentaremos a seguir o adoecimento do familiar e as contribuições dos serviços de saúde com os dependentes e seus respectivos cuidadores. Daremos destaque à Estratégia de Saúde da Família, local onde foi realizada a pesquisa. 


\section{O Adoecer e os Serviços de Saúde}

Em relação ao problema de saúde dos dependentes, cinco deles sofreram acidente cerebrovascular (AVC). Apenas uma das cuidadoras não tinha clareza do problema de saúde da pessoa cuidada.

[...]. Só que até então eu não sei se ela tem um começo de alzheimer, mas eu acredito que não. Eu acho que é uma variação da idade, as coisas que ela fala, tem hora que ela varia, confunde muito a televisão com a realidade (C1).

Segundo Medina, Shirassu e Goldfeder (2004), vários fatores associam-se ao AVC, como herança genética, comportamentais (tabagismo, etilismo, alimentação inadequada), fatores socioeconômicos, doenças associadas (hipertensão arterial), entre outras.

Por tratar-se de uma doença crônica que deixa sequelas, o AVC faz com que a pessoa se torne dependente de alguém para a realização de tarefas cotidianas, necessitando, assim, da figura do cuidador.

Com a limitação de uma doença crônica, a pessoa precisa de auxílio para a realização de compras, cuidar das finanças, tomar banho, vestir-se, ir ao banheiro, alimentar-se, sentar e levantar de cadeiras e cama (MEDINA apud ALTAFIN, 2007).

A maioria dos sujeitos tem clareza do problema de saúde que acometeu seu familiar, porém não foram todos que receberam orientações sobre a doença e os cuidados rotineiros com o doente. Quatro cuidadoras receberam explicações sobre a doença, sendo que uma delas relatou tê-las obtido quando se mudou para o interior. Uma das cuidadoras não se lembrou de obter orientações, devido a ter iniciado as práticas de cuidado ainda na infância. Outra cuidadora informou não ter recebido informações do serviço de saúde. Mas, relacionado à atividade de cuidar, as cuidadoras relataram ter aprendido com a prática, sendo que não foram orientadas como realizar os procedimentos com o doente. 
Eu nem lembro porque a gente era muito pequena. A única coisa que eu lembro é que ela ficou muito tempo internada em São Paulo. A gente nunca pôde conviver como mãe e filha. [...] A gente não sabia o que era brincar, às vezes a gente fazia casinha no quintal, mas era rapidinho, ficava olhando no relógio, quatro horas já tinha que fazer a janta, pra não descuidar dela. Ou a gente ficava na beira da cama e ela contava historinha pra gente, era nossa vida (C5).

De acordo com Mendes (2004, p. 178),

[...] os familiares são informados, superficialmente, sobre as características e demandas desses cuidados, que envolvem locomoção do paciente, sua higiene diária, administração de remédios, dieta alimentar quando necessária, fisioterapia e retornos para acompanhamento médico. Além disso, esses familiares não são informados, suficientemente, sobre as características de uma doença crônico-degenerativa.

Cerqueira e Oliveira (2002) observam a necessidade de oferecer apoio aos cuidadores. Pereira (2000) destaca que nos países desenvolvidos o cuidador conta com uma rede de serviços públicos que garante suporte domiciliar. O cuidador é considerado uma necessidade social, inscrito na esfera pública.

Em nosso país, os cuidadores não têm essa visibilidade como nos países desenvolvidos, mas alguns aspectos do sistema de saúde têm colaborado para reverter o fato, como a implantação da Estratégia Saúde da Família (ESF). Esta teve início em 1994, como uma estratégia do Ministério da Saúde (MS), para mudar a forma tradicional de prestação de assistência, visando estimular a implantação de um novo modelo de Atenção Primária que resolvesse a maior parte dos problemas de saúde (BESEN et al., 2007).

Segundo Bernardino et al. (2005), a ESF contribuiria para a reorganização do modelo assistencial. Essa reorganização pressupõe uma nova abordagem na relação entre o serviço de saúde e a população, integrando práticas individuais e coletivas, curativas, preventivas e de promoção da saúde dos indivíduos e da família, tanto dos adultos, quanto crianças, ou idosos, de forma integral e contínua.

Com as atividades dos profissionais da Estratégia de Saúde da Família, muitos dos cuidadores revelaram sentir melhoria no atendimento, especialmente domiciliar. 
Bom. Depois que se transformou em Saúde da Família ficou melhor. As visitas são boas, a gente conversa, tem mais liberdade. Antes vinha no Posto era aquela correria. Em casa a gente pergunta, vêem a pressão, brinca com ele. Tá bem melhor assim (C6).

A maioria das cuidadoras revela que o serviço de saúde melhorou com a passagem para Estratégia Saúde da Família. Uma cuidadora afirma que as visitas domiciliares deveriam ser mais contínuas. Um sujeito não demonstrou muita clareza sobre quem realiza as visitas domiciliares em sua residência, não expressando sua opinião sobre o Programa. Notamos também que os sujeitos centram a atenção à saúde de seus familiares na figura do médico, embora a equipe conte com diversos profissionais que realizam atividades com os cuidadores e seus familiares.

Nas USF, onde foi desenvolvida a pesquisa, o atendimento aos cuidadores e seus familiares é realizado por toda a equipe de saúde da família, dentro da especificidade de cada profissão e de acordo com a necessidade do paciente e seu cuidador. São realizados curativos; aferidas pressões arteriais; entrega e orientações sobre a tomada de medicações; exercícios de fisioterapia; atividades desenvolvidas pela terapia ocupacional; orientações nutricionais; previdenciárias; sobre recursos socioassistenciais; exercícios de fonoaudiologia; tratamento odontológico; cuidados com o paciente (higiene, prevenção de escaras, manuseio e limpeza de sondas, dentre outros).

O cuidado prestado pelas equipes de saúde da família ocorre na USF e no domicílio, facilitando o contato com o paciente e cuidador e diminuindo as dificuldades com transporte. O contato com a residência facilita as orientações e adaptações necessárias de acordo com a realidade da família. As visitas domiciliares são variáveis e distribuídas ao longo da semana de acordo com o estado de saúde dos pacientes.

Além disso, visando o atendimento integral e a toda família foi desenvolvido, no ano de 2007, um Grupo para Cuidadores com o objetivo de oferecer um espaço de cuidado, de escuta, de valorização pessoal e de possibilidades de potencializar mudanças na vida pessoal e familiar; propiciar o autoconhecimento e autoaceitação; possibilitar vivências corporais e artísticas integrando a relação corpo e mente; promover um espaço significativo para a expressão dos sentimentos pessoais e o acolhimento dessas expressões; valorizar o espaço pessoal de cada um dentro do seu meio familiar; fortalecer 
as relações individuais e grupais; abrir espaço para que cada pessoa possa redescobrir desejos, emoções e sonhos que guardava para si e promover a reflexão para a busca da concretização de objetivos futuros.

Era bom, podíamos aprender mais e desabafar [...]. (C6).

Conforme Cruz e Hamdan (2008), os grupos de apoio são uma estratégia de intervenção com os cuidadores, pois servem como espaço de troca de experiências entre os cuidadores e de esclarecimentos sobre a doença do familiar.

Segundo o Ministério da Saúde, os grupos de cuidadores são espaços de trocas de experiências, nos quais os cuidadores podem conversar, aprender e ensinar a arte de cuidar, formando uma rede de apoio entre eles (BRASIL, 2008).

As participações nas atividades grupais eram de suma importância para a valorização das cuidadoras, possibilitando aprendizagem, troca de experiências entre os membros do grupo e um espaço de autocuidado.

Diante dos fatos apresentados, acreditamos na importância das ações individuais e grupais dos profissionais da ESF, que atuem no cuidado ao doente crônico e seus familiares, contribuindo para melhoria da qualidade de vida de ambos.

\section{Considerações Finais}

Este trabalho buscou analisar o cotidiano, as alterações ocorridas na vida dos cuidadores após assumirem os cuidados de seus familiares e apontar como a Estratégia Saúde da Família contribuiu com o processo de cuidar vivenciado pelos cuidadores. Para isso, utilizamos os depoimentos de sete (7) cuidadores cadastrados em duas Unidades de Saúde da Família de São Carlos-SP.

Também constatamos que as cuidadoras recebem pouco apoio dos familiares para os cuidados, e, com isso, sentem a sobrecarga com a tarefa de cuidar, deixando de realizar muitas práticas cotidianas, como atividades sociais, deixar de trabalhar e relacionadas ao autocuidado.

As cuidadoras apontaram sobre as modificações econômicas, devido às modificações na residência e no acréscimo das despesas domésticas. Além disso, a 
aquisição de equipamentos como cama hospitalar, cadeira de rodas, cadeira de banho não foram obtidos por meio do poder público, mas sim pela ajuda de outros cuidadores que tiveram seus familiares falecidos, mediante aluguel ou criatividade de familiares.

Quanto ao significado do cuidar revelaram que esse está vinculado a valores morais, às atividades práticas e a sentimentos afetivos.

Os dados evidenciaram que muitas das cuidadoras tiveram dificuldades para lidar com o doente. Devido à falta de orientações, aprenderam a realizar a atividade com a prática. Porém, com os atendimentos dos profissionais da Estratégia Saúde da Família houve melhoria nos cuidados de seus familiares, especialmente pelo contato domiciliar. Além disso, a equipe possibilitava vivências grupais, as quais contribuíam para a troca de experiências entre os cuidadores, espaço de escuta e aprendizagem.

Consideramos por meio do estudo, a importância de se dar visibilidade ao papel do cuidador, construindo espaços que valorizem e trabalhem questões cotidianas relacionadas aos cuidados com o doente e com o próprio cuidador. Destacamos o território da Estratégia de Saúde da Família como um terreno fértil para essas ações, considerando a proximidade com as famílias e a valorização e concretização da proposta de atendimento integral e humanizado à toda população.

Também são necessários novos estudos, a fim de ampliar o conhecimento sobre os cuidadores, conhecendo suas demandas e possibilitando o levantamento de novas estratégias de intervenção a essa população.

\section{Referências}

ALTAFIM, L. Z. M. Intervenção: suporte para cuidadores de doentes crônicos através do ensaio. 2007. Dissertação (Mestrado) - Universidade Federal de São Carlos, São Carlos.

BERNARDINO, M. T. S. M. et al. Consensos e divergências: a capacitação profissional das equipes de saúde da família no município de São Carlos (SP). Trabalho, Educação e Saúde, Rio de Janeiro, v. 3, n. 1, p. 75-89, 2005.

BESEN, C. B. et al. A estratégia saúde da família como objeto de educação em saúde. Saúde e Sociedade, São Paulo, v. 16, n. 1, p. 57-68, jan./abr. 2007.

BOFF, L. Cuidado: o ethos do humano. In: Saber cuidar: ética do humano compaixão pela terra. Petrópolis, Rio de Janeiro: Vozes, 1999. p. 31- 86.

BRASIL. Ministério da Saúde. Guia prático do cuidador. Brasília: Ministério da Saúde, 
2008.

BRITO, D. C. S. Cuidando de quem cuida: estudo de caso sobre o cuidador principal de um portador de insuficiência renal crônica. Psicologia em Estudo, Maringá, v. 14. n. 3, p. 603607, 2009.

CATTANI, R. B.; GIRARDON-PERLINI, N. M. O. Cuidar do idoso doente no domicílio na voz de cuidadores familiares. Revista Eletrônica de Enfermagem, v. 6, n. 2, p. 254-271, 2004. Disponível em: <http://www.fen.ufg.br/revista/revista6_2/pdf/Orig11_idoso.pdf >. Acesso em: 6 ago. 2007.

CERQUEIRA, A. T. A. R.; OLIVEIRA, N. I. L. Programa de apoio a cuidadores: uma ação terapêutica e preventiva na atenção à saúde dos idosos. Psicologia USP, São Paulo, v. 13, n. 1, p. 133-150, 2002.

CONCEIÇÃO, L. F. S. Saúde do idoso: orientações ao cuidador do idoso acamado. Revista Médica de Minas Gerais, Belo Horizonte, v. 20, n. 1, p. 81-89, 2010.

CRUZ. M. N.; HAMDAN, A. C. O impacto da doença de Alzheimer no cuidador. Psicologia em Estudo, Maringá, v. 13, n. 2, p. 223-229, 2008.

ELIAS, P. E. M. Estrutura da atenção à saúde no Brasil. In: COHN, A.; ELIAS, P. E. M. A saúde no Brasil: políticas e organização de serviços. 2. ed. São Paulo: Cortez: Cedec, 1998. p. 57-117.

FELGAR, J. A. S. Uma expressão da linguagem numérica. In: KARSCH, U. M. S. (Org.). Envelhecimento com dependência: revelando cuidadores. São Paulo: Educ, 2004. p. 47-85.

FLORIANI, C. A. Cuidador familiar: sobrecarga e proteção. Revista Brasileira de Cancerologia, Rio de Janeiro, v. 50, n. 4, p. 341-345, 2005.

FONSECA, N. R.; PENNA, A. F. G.; SOARES, M. P. G. Ser cuidador familiar: um estudo de caso sobre as consequências de assumir este papel. Physis Rebista de Saúde Coletiva, Rio de Janeiro, v. 18, n. 4, p. 727-743, 2008.

INOCENTI, A.; RODRIGUES, I. G.; MIASSO, A. I. Vivências e sentimentos do cuidador familiar do paciente oncológico em cuidados paliativos. Revista Eletrônica de Enfermagem, Goiânia, v. 11, n. 4, p. 858-865, 2009. Disponível em:

<http://www.fen.ufgbr/revista/v11/n4/m4a11.htm>. Acesso em: 1 jun. 2010.

KARSCH, U. M. Cuidadores familiares de idosos: parceiros da equipe de saúde. Serviço Social e Sociedade, São Paulo, ano XX, n. 59, mar. 1999.

KARSCH, U. M. Idosos dependentes: famílias e cuidadores. Cadernos de Saúde Pública, Rio de Janeiro, v. 19, n. 3, p. 861-866, maio/jun. 2003.

LEVORATO, C. D. O cuidar para a morte. 2006. Trabalho de Conclusão de Curso (Graduação em Serviço Social) - Universidade Estadual de Londrina, Londrina. 
MEDINA, M. C. G.; SHIRASSU, M. M.; GOLDFEDER, M. C. Das incapacidades e do acidente cerebrovascular. In: KARSCH, U. M. S. (Org.). Envelhecimento com dependência: revelando cuidadores. São Paulo: Educ, 2004. p. 199-214.

MENDES, P. B. M. T. Cuidadores: heróis anônimos do cotidiano. In: KARSCH, U. M. S. (Org.). Envelhecimento com dependência: revelando cuidadores. São Paulo: Educ, 2004. p. 171-197.

MENDES, P. B. M. T. Quem é o cuidador? In: DIAS, E. L. F.; WANDERLEY, J. S.; MENDES, R. T. (Org.). Orientações para cuidadores informais na assistência domiciliar. 2. ed. Campinas: Ed. UNICAMP, 2005. p. 19-33.

MINAYO, M. C. S. (Org.). Pesquisa social: teoria, método e criatividade. 11. ed. Rio de Janeiro: Vozes, 1999.

PEREIRA, M. T. M. A. O cotidiano dos cuidadores de doentes com aids, no município de Londrina. 2000. Dissertação (Mestrado) - Universidade Federal de São Paulo, São Paulo, 2000.

SANTOS, S. M. A. Idosos, família e cultura: um estudo sobre a construção do papel do cuidador. Campinas: Editora Alínea, 2003.

SILVEIRA, T. M.; CALDAS, C. P. Cuidando de idosos altamente dependentes na comunidade: um estudo sobre cuidadores familiares principais. Cadernos de Saúde Pública, Rio de Janeiro, v. 22, n. 8, p. 1629-1638, ago. 2006.

WANDERLEY, M. B. et al. Publicização do papel do cuidador domiciliar. São Paulo: IEE/PUC-SP. Brasília: Secretaria de Assistência Social/MPAS, 1998.

Recebido em: 15/08/2010

Aprovado em: 20/09/2010 